\title{
Stable operation of a high-voltage high-current dc photoemission gun for the bunched beam electron cooler in RHIC
}

\author{
X. Gu๑, ${ }^{*}$ Z. Altinbas, S. Badea, D. Bruno, L. Cannizzo, M. Costanzo, A. Drees, A. V. Fedotov, \\ W. Fischer, D. Gassner, M. Gaowei, P. Inacker, J. Jamilkowski, D. Kayran, J. Kewisch, \\ C. J. Liaw, C. Liu, M. Mapes, K. Mernick, C. Mi, T. A. Miller, M. Minty, L. Nguyen, V. Ptitsyn, \\ J. Sandberg, V. Schoefer, S. Seletskiy, L. Smart, A. Sukhanov, P. Thieberger, J. Tuozzolo, \\ E. Wang, A. Zaltsman, He Zhao, and Zhi Zhao \\ Brookhaven National Laboratory, Upton, New York 11973, USA
}

A. Bartnik and K. Smolenski

Cornell University, Ithaca, New York 14850, USA

(Received 31 October 2019; published 28 January 2020)

\begin{abstract}
The Low Energy RHIC electron Cooling (LEReC) project at Brookhaven National Laboratory recently demonstrated for the first time cooling of hadron bunches with radio-frequency (rf) accelerated electron bunches. LEReC uses a high-voltage photoemission electron gun with stringent requirements for beam current, beam quality, and stability. The electron gun has a photocathode with a high-power fiber laser, and a novel cathode production, transport, and exchange system. It has been demonstrated that the high-voltage photoemission gun can continually produce a high-current electron beam with a beam quality suitable for electron cooling. We describe the operational experience with the LEReC dc photoemission gun in RHIC and discuss the important aspects needed to achieve the required beam current, beam quality, and stability.
\end{abstract}

DOI: 10.1103/PhysRevAccelBeams.23.013401

\section{INTRODUCTION}

\section{A. Motivation}

The Relativistic Heavy Ion Collider (RHIC) [1-4] at Brookhaven National Laboratory (BNL) is a circular collider that has operated successfully for almost two decades. It has two rings in a horizontal plane with two head-on beam-beam interaction points (IP6 and IP8) and four crossing points without collisions (IP2, IP4, IP10, and IP12). To explore the QCD phase diagram, which is one of the important issues in the nuclear physics field [5,6], a Beam Energy Scan (BES) program is carried out in RHIC $[7,8]$. The BES program operates at various ion beam energies [8] which are below the normal operating range of the collider.

For a collider, the luminosity is one of the most important figures of merit. The luminosity formula for round Gaussian and equal beams at the interaction point (IP), as is the case in RHIC, can be expressed [9] as

\footnotetext{
*xgu@bnl.gov
}

Published by the American Physical Society under the terms of the Creative Commons Attribution 4.0 International license. Further distribution of this work must maintain attribution to the author(s) and the published article's title, journal citation, and DOI.

$$
L=n_{b} \frac{f_{c}}{4 \pi} \frac{N^{2}}{\sigma^{2}} H
$$

where $n_{b}$ is the collision bunch number, $f_{c}$ is the collision frequency, $\sigma$ is the transverse rms beam size at the IP, and $N$ is the particle number per ion bunch. $\mathrm{H}$ is a geometric factor that accounts for the hourglass and crossing angle effect. For the head-on beam-beam collisions in RHIC, $\mathrm{H}$ includes only the hourglass effect. For a symmetric, round Gaussian beam with equal beta functions at the IP, it can be detailed as

$$
H=\int_{-\infty}^{\infty} \frac{d t}{\sqrt{\pi}} \frac{e^{-t^{2}}}{1+\left(\frac{t}{t_{h}}\right)^{2}}
$$

where $t_{h}=\beta^{*} / \sigma_{l} . \beta^{*}$ is the beta function at the IP. The geometric factor $\mathrm{H}$ increases with increasing $t_{h}$. Therefore, a smaller longitudinal beam size $\sigma_{l}$, as well as a smaller transverse beam size $\sigma$ will both increase the luminosity.

For the BES program, the planned beam energies are $3.85,4.59,5.75,7.3$, and $9.8 \mathrm{GeV} /$ nucleon. At these energies, the luminosity is limited due to the relatively short ion beam lifetime and fast growth of both the transverse and longitudinal beam emittance because of several physical effects [10-13], such as intrabeam scattering (IBS), space charge, and beam-beam effects. 


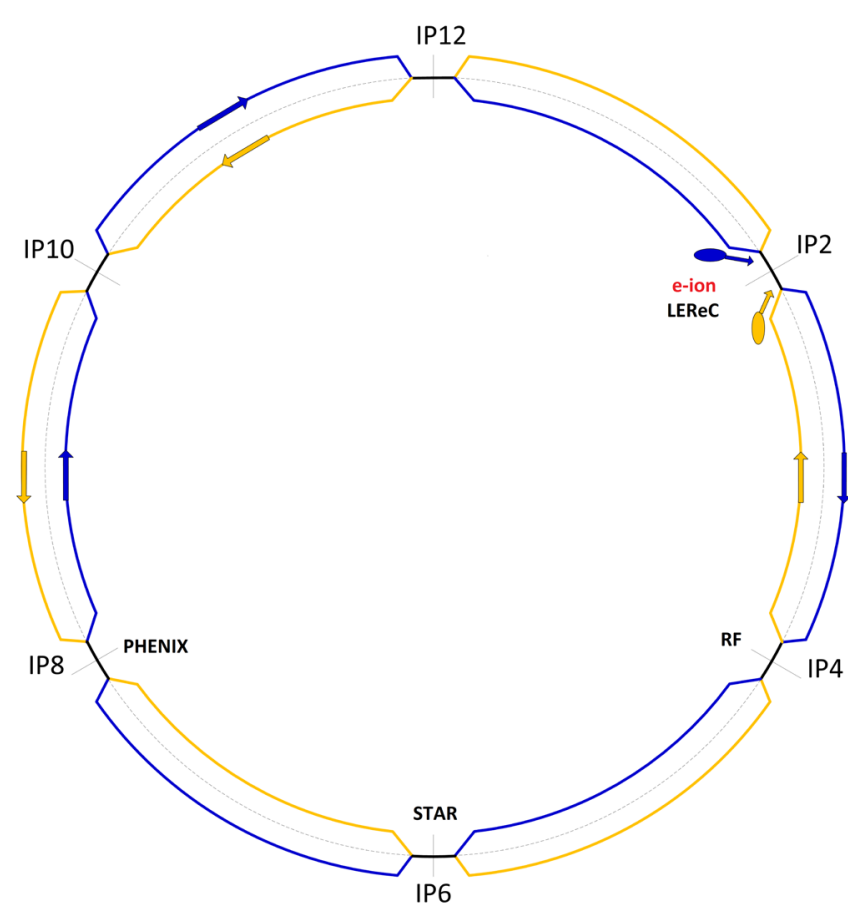

FIG. 1. Conceptual layout of RHIC showing the location for the low-energy electron cooling. The head-on ion beam-beam interactions occur in IP6 (STAR), while the electron-ion cooling is achieved in IP2.

To improve the ion beam lifetime, affected by space charge and beam-beam effects, three new $9 \mathrm{MHz}$ rf cavities were installed in each RHIC ring and new working points were explored [14]. To improve the integrated luminosity and lifetime limited by IBS, a reduction of the transverse and longitudinal beam sizes $\sigma$ and $\sigma_{l}$, will be achieved using the Low Energy RHIC electron Cooler (LEReC) [15-22] located in IR2 (see Fig. 1).

\section{B. The LEReC Accelerator}

The required LEReC beam parameters for cooling at the lowest BES energy are summarized in Table I. A photoemission electron gun injector, followed by a superconducting rf cavity for acceleration [23-28], was adapted as an electron source for LEReC. This choice took advantage of the high-voltage electron gun experience and the excellent beam quality achieved at Cornell University [29-37], in Japan [38-44] and at Jefferson National Lab [45-48]. It has been demonstrated that a high-voltage dc photoemission gun can have good beam quality, such as low emittance [30,31] and high average current [29].

The LEReC dc photoemission gun commissioning started in 2017 and the required beam parameters were successfully achieved during the commissioning in 2018 [15-20]. LEReC operated with an average current of up to $30 \mathrm{~mA}$ and demonstrated the design beam quality with low emittance and energy spread. Recently, using the LEReC accelerated electron beam, 3-dimensional bunched
TABLE I. The LEReC electron and ion beam parameters in 2019.

\begin{tabular}{|c|c|c|c|}
\hline Parameters & Unit & Value & Value \\
\hline Electron beam & & Operated & Designed \\
\hline Kinetic energy & $\mathrm{MeV}$ & \multicolumn{2}{|c|}{$1.6 / 2.0$} \\
\hline Energy spread & $10^{-4}$ & $<5$ & 5 \\
\hline Bunch charge & $\mathrm{pC}$ & $<130$ & 130 \\
\hline Bunches per train & & 30 & 30 \\
\hline $\begin{array}{l}\text { Macrobunch repetition } \\
\text { frequency }\end{array}$ & $\mathrm{MHz}$ & \multicolumn{2}{|c|}{9.1} \\
\hline $\begin{array}{l}\text { Microbunch repetition } \\
\text { frequency }\end{array}$ & $\mathrm{MHz}$ & \multicolumn{2}{|c|}{704} \\
\hline $\mathrm{CW}$ beam current & $\mathrm{mA}$ & $14-20$ & 35 \\
\hline rms emittance $\varepsilon_{n}$ & $\mu \mathrm{m}$ & $0.9(70 \mathrm{pC})$ & 2.5 \\
\hline \multicolumn{4}{|l|}{ Ion beam } \\
\hline Species & \multicolumn{3}{|c|}{$\mathrm{Au}$} \\
\hline Energy & $\mathrm{GeV} /$ nucleon & \multicolumn{2}{|c|}{$3.85 / 4.59$} \\
\hline Energy spread & $10^{-4}$ & \multicolumn{2}{|c|}{ 4-4.5 } \\
\hline Emittance (rms) & $\mu \mathrm{m}$ & 1.5 & 2.5 \\
\hline Intensity/bunch & $10^{9}$ & \multicolumn{2}{|c|}{0.7} \\
\hline rms bunch length $\sigma_{l}$ & Ns & \multicolumn{2}{|c|}{10} \\
\hline Radio frequency & $\mathrm{MHz}$ & \multicolumn{2}{|c|}{9.1} \\
\hline rf voltage/turn & $\mathrm{kV}$ & \multicolumn{2}{|c|}{180} \\
\hline rf harmonic number & & \multicolumn{2}{|c|}{120} \\
\hline
\end{tabular}

beam cooling was successfully demonstrated for the first time $[21,22]$.

Figure 2 shows a simplified schematic view of the LEReC system. The LEReC accelerator has several beam lines: the injection line, the transport line, the diagnostic line, the dogleg, the yellow and the blue cooling section, and the extraction line. More details about the LEReC system can be found in Refs. [17,21].

The injection line $(\sim 7 \mathrm{~m})$ was built with a low power beam dump in 2017 while the other beamlines were still under construction. It was used for the commissioning of the dc photoemission gun systems as well as other systems, such as the laser system, the magnets, the timing system, the machine protection system and many diagnostic devices. The $704 \mathrm{MHz}$ SRF booster acceleration cavity and the $2.1 \mathrm{GHz}$ linearization cavity were installed in 2018 .

The transport line $(\sim 32 \mathrm{~m})$ is used to propagate the electron beam from the source to the cooling section while preserving the beam quality. It also has two rf cavities; they are the $9 \mathrm{MHz}$ energy correction cavity and the $704 \mathrm{MHz}$ dechirping cavity.

The diagnostic line has a $704 \mathrm{MHz}$ deflecting cavity and a YAG screen for time-dependent energy spread measurements. After beam matching in the dogleg (solenoids are not shown in Fig. 2), the beam is propagated through the yellow cooling section $(\sim 20 \mathrm{~m})$ and the blue cooling section $(\sim 20 \mathrm{~m})$. At last, the electron beam is deflected into the extraction line (magnets are not shown here) and the high-power dump.

The time structure of the RHIC ion beam bunch and the LEReC electron beam are depicted in Fig. 3. In RHIC, for 


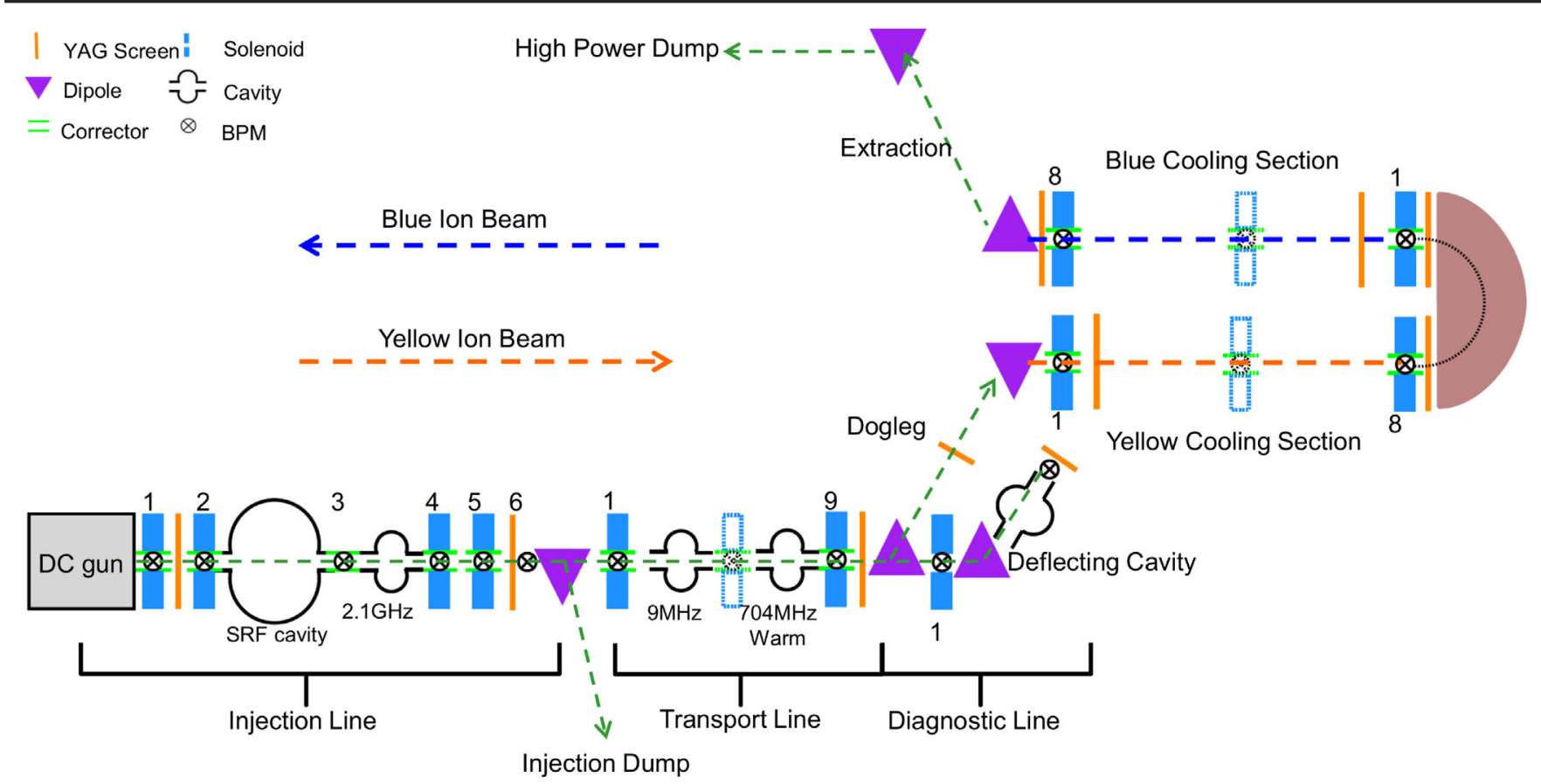

FIG. 2. Schematic layout of the LEReC Accelerator. The electron beam trajectory is shown as a green dashed line. The blue and yellow ion beam directions are also shown in the plot. Dimensions not to scale.

the low-energy ion beam, the $9 \mathrm{MHz}$ rf cavity was used with a harmonic number of 120 . There are 9 buckets left empty for the beam abort gap and 111 buckets filled with ion bunches. The top plot of Fig. 3 shows the structure of the RHIC ion beam.

For the electron beam in LEReC, electron microbunches are accelerated by the $704 \mathrm{MHz}$ SRF booster cavity. To cool an ion bunch with full length of about $50 \mathrm{~ns}$, a macrobunch of electrons consisting of 30 individual microbunches spaced by $1.42 \mathrm{nsec}$ is employed. The structure of one electron macrobunch and one ion beam bunch are shown at the bottom of Fig. 3. A $704 \mathrm{MHz}$ drive laser [49] and an ultrafast pulse picker [50] have been developed to produce $9 \mathrm{MHz}$ optical macrobunches (30 pulses per bunch).

The LEReC accelerator has several beam modes. These are pulsed mode, $76 \mathrm{kHz}$ mode (1 pulse per RHIC turn), and continuous-wave $(\mathrm{CW})$ mode. The pulsed mode can have 1-500 consecutive macrobunches with a repetition rate of $1 \mathrm{~Hz}$. This mode is used for optics work, beam quality measurement, as well as hardware and software commissioning. The $76 \mathrm{kHz}$ mode can have several macrobunches with a repetition rate of $76 \mathrm{kHz}$. Typically, this mode is used to overlap the electron beam (5 macrobunches) with the ion beam (6 bunches), for cooling optimization. The $\mathrm{CW}$ mode has one macrobunch repeating with a $9 \mathrm{MHz}$ repetition rate. It can cover all 120 ion beam rf buckets which have a $76 \mathrm{kHz}$ revolution frequency. This mode is used for nominal physics operation.

The paper is organized as follows. In Sec. I, the LEReC project is introduced, as well as the requirements of electron beam parameters and LEReC accelerator systems.
In Sec. II, the LEReC dc photoemission gun system with some modifications and its conditioning experience are presented. The electron gun high-voltage power supply (HVPS) ripple and its effects on the electron beam energy are evaluated in Sec. III. In Sec. IV, the beam slice emittance is measured via a solenoid scan method. The LEReC cathode insertion system, which is required for the continuous RHIC physics operation, is introduced in Sec. V. The experience of the HV dc photoemission gun stable operation during 2019 is reviewed in Sec. VI and the high-current $\mathrm{CW}$ beam operation experience is presented in Sec. VII. Finally, a summary is given in Sec. VIII.

\section{HIGH VOLTAGE DC PHOTOEMISSION ELECTRON GUN}

\section{A. DC photoemission gun system}

Based on its existing high-voltage photoemission gun, the LEReC electron gun was built by Cornell University with some small refinements. The mechanical components and design of the high-voltage dc photoemission gun system have been described in Refs. [29-36]. A schematic view of the LEReC high-voltage electron gun system is given in Fig. 4.

It includes a high-voltage power supply and some electron gun components. The HVPS has three components: controller, inverter, and multiplier. The multiplier is inside of the $\mathrm{SF}_{6}$ chamber at $6.9 \mathrm{kPa}$ (70 psi). The HVPS is rated at $700 \mathrm{kV}$ and was tested to $600 \mathrm{kV}$ without load.

On the electron gun chamber side, there is a cathode that connects to the HVPS through a stem electrode. There is an 
120 ion bunches structure including 9 empty as an abort gap

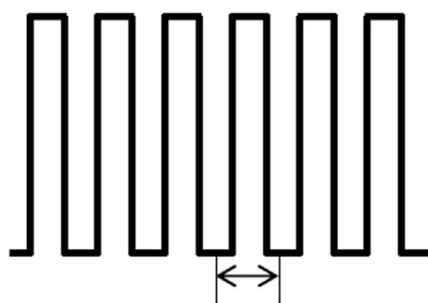

$\mathrm{T}=110$ nsec, $\mathrm{f}=9 \mathrm{MHz}$

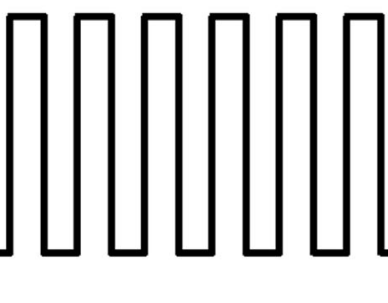

$\mathrm{T}=1.42 \mathrm{~ns}, \mathrm{f}=704 \mathrm{MHz}, 30$ micro-bunches

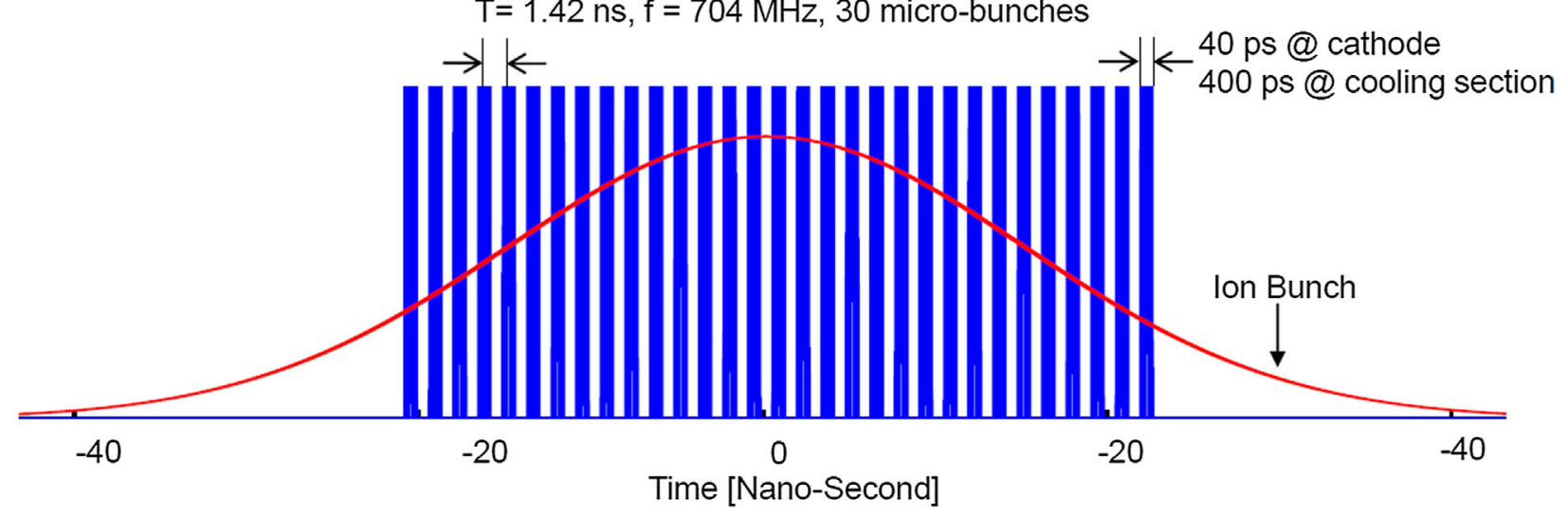

FIG. 3. Time structure of a RHIC ion bunch and a LEReC electron macrobunch. anode which is connected to the ground through an anode bias power supply and an ampere meter. To prevent ions from streaming back to the cathode during the $\mathrm{CW}$ electron beam operation, the anode bias power is set to $2 \mathrm{kV}$. To simplify the electron gun system for LEReC operation, the gap between the anode and cathode is fixed at $50 \mathrm{~mm}$ instead of a variable gap.

Between the electron gun chamber and the $\mathrm{SF}_{6}$ chamber, there is a $500 \Omega$ running resistor (R2) to connect the cathode to the HVPS. If conditions with high radiation ( $\geq 200 \mathrm{mrad} / \mathrm{h}$ ) in the electron gun persisted during operation, the dc photoemission gun needed to be reconditioned. For conditioning or reconditioning the gun, the resistor between them is changed to a $66.7 \mathrm{M} \Omega$ resistor (R1), to limit the discharge currents, thus avoiding damage to the cathode and anode surface.

In the past, this change required opening the $\mathrm{SF}_{6}$ tank for the resistor replacement which required a minimum of 12 hours. A resistor switch mechanism was designed and implemented between the gun electrodes and the HVPS, to avoid the time-consumed SF6 pumping and evacuating each time the resistors needed to be exchanged. With this switchable resistor design, the mode switch can be done within 45 minutes. This significantly reduced the access time when a different operation mode was required.

In this system both resistors ( $\mathrm{R} 1$ and $\mathrm{R} 2$ ) are permanently connected in series (Fig. 4). The resistor R1 can be bypassed by shorting it out with a movable conductor (MC) which is a metal ball. The metal ball connects to a steel cable which is pulled out of a spring-loaded reel and an insulated string (red wire in Fig. 5). When the MC is moved to the P1 position, the switch around R1 in Fig. 4 is open and the electron gun is in the conditioning mode; when the movable conductor is at the $\mathrm{P} 2$ position, the running resistor (R2) is connected between the electron gun and the HVPS.

As shown in Fig. 5, the other end of this insulating string is attached to another reel driven by a stepper motor. At present, this stepper motor is locally controlled, but adding

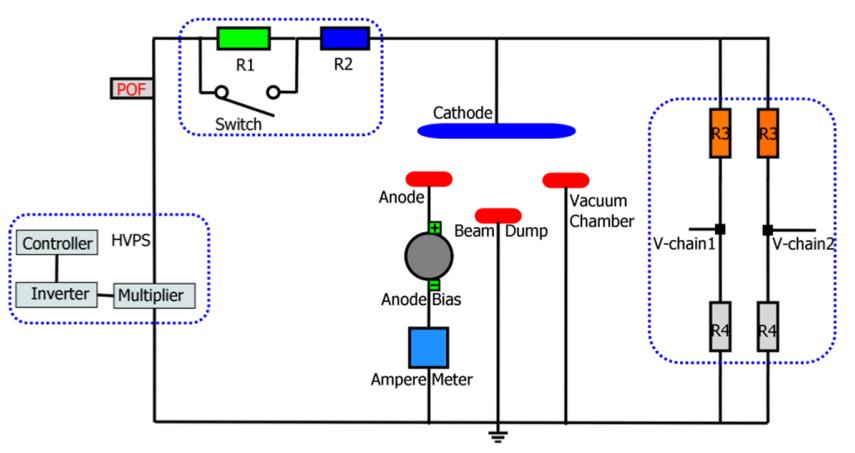

FIG. 4. Schematic view of the LEReC high-voltage dc photoemission gun. There are four major components: the HVPS, the switchable resistors, the gun electrodes, and the resistor chains. 


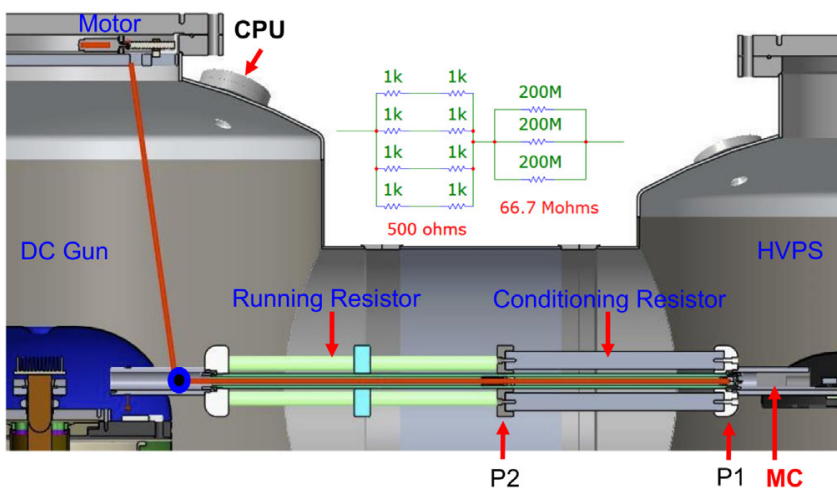

FIG. 5. The resistor switch mechanism located between the dc photoemission gun and the HVPS.

remote control to the moter is planned in order to avoid having to access the RHIC tunnel, which is a radiation area.

There are two resistor chains outside of the electron gun ceramic insulator. To measure the HVPS voltage, each resistor chain has a smaller resistor $(\mathrm{R} 4=72 \Omega$ ) for an output voltage. The voltage measured from the $\mathrm{V}$ chain can be used for HVPS voltage ripple regulation as well as for machine protection. To have a higher output voltage signal for regulation, the resistor R3 has been changed from its original design value of $7000 \mathrm{M} \Omega$ to $650 \mathrm{M} \Omega$. The parameters of the LEReC electron gun system are listed in Table II.

The total HVPS output current has three components. It includes the leakage current through the electron gun vacuum chamber and anode during the gun conditioning; it includes the current through the two resistor chains caused by the high voltage in the circuit; and it also includes the electron beam current from the cathode during operation. The total HVPS output current is measured by a power-over-fiber (POF) system [51]. The sampling rate of the POF is $850 \mathrm{~Hz}$, and the resolution is $0.1 \mu \mathrm{A}$.

The total output current can also be obtained from the HVPS itself with a resolution of $0.1 \mathrm{~mA}$. The current from the HVPS is used for self-protection by setting a current limit. The current limit is set to $2 \mathrm{~mA}$ during

TABLE II. LEReC dc photoemission gun parameters.

\begin{tabular}{lcc}
\hline \hline Parameters & Unit & Value \\
\hline HVPS & $\mathrm{kV}$ & 700 \\
Operating voltage & $\mathrm{kV}$ & 375 \\
R1 & $\Omega$ & 500 \\
$\mathrm{R} 2$ & $\mathrm{M} \Omega$ & $100 / 66.7$ \\
R3 & $\mathrm{M} \Omega$ & 650 \\
Gun voltage/HVPS & & $0.87 / 0.91$ \\
Gun capacitance & $\mathrm{pF}$ & 200 \\
Anode voltage & $\mathrm{kV}$ & 2 \\
rms ripple & $\mathrm{kV}$ & $0.05 @ 17 \mathrm{~mA}$ \\
R4 & $\Omega$ & 72 \\
\hline \hline
\end{tabular}

${ }^{\mathrm{a} C}$ Conditioning mode. nominal pulsed mode operation and is increased during CW operation.

The LEReC electron gun system is located inside the RHIC tunnel, where it is exposed to potential radiation from beam losses. At the beginning of the 2017 RHIC run, there were several HVPS inverter upsets. It is suspected that radiation caused the malfunction or failure of the controller, which resulted in the inverter upset. To avoid this issue, the controller and the inverter were first shielded by a $10 \mathrm{~cm}$ thick concrete wall. Later, the controller was moved out of the tunnel. After that, no more inverter faults were observed.

\section{B. Photoemission gun conditioning}

The high-voltage photoemission gun was assembled and first conditioned at Cornell University. After disassembling and moving it into the RHIC tunnel, it was conditioned again. Figure 6 shows the voltage progress during two conditioning periods. During the gun conditioning at BNL, a script was created to automate the conditioning process. In both Cornell University and BNL cases, it took about 45 hours to reach $440 \mathrm{kV}$.

Several signals are monitored during the dc photoemission gun conditioning. They are the HVPS voltage, the gun vacuum level, the radiation level, and the POF current. These four signals are shown in Fig. 7. The radiation is measured by a Canberra detector [50] placed at the exit of the electron gun chamber.

The total average leakage current from the HVPS is measured by the POF. It is notable that the POF signal (red line), which may indicate the discharge spikes inside of the electron gun, has a low noise level at a low HVPS voltage. With the HVPS voltage increasing, the noise level on the POF signal grows, as well as the base line which is the leakage current from the HVPS to the two resistor chains.

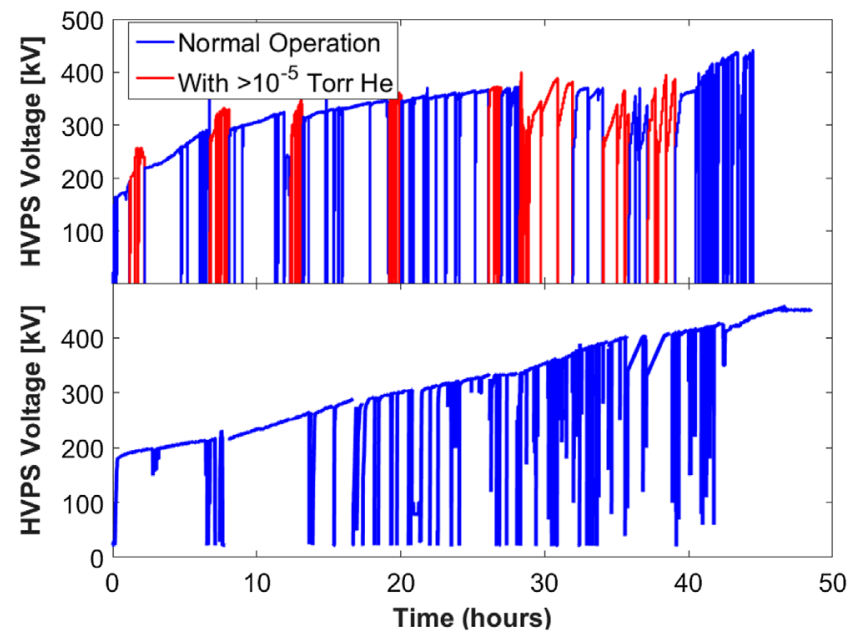

FIG. 6. HVPS voltage progress during the dc photoemission gun conditioning. The top and bottom plot depict the results from Cornell University and BNL, respectively. 


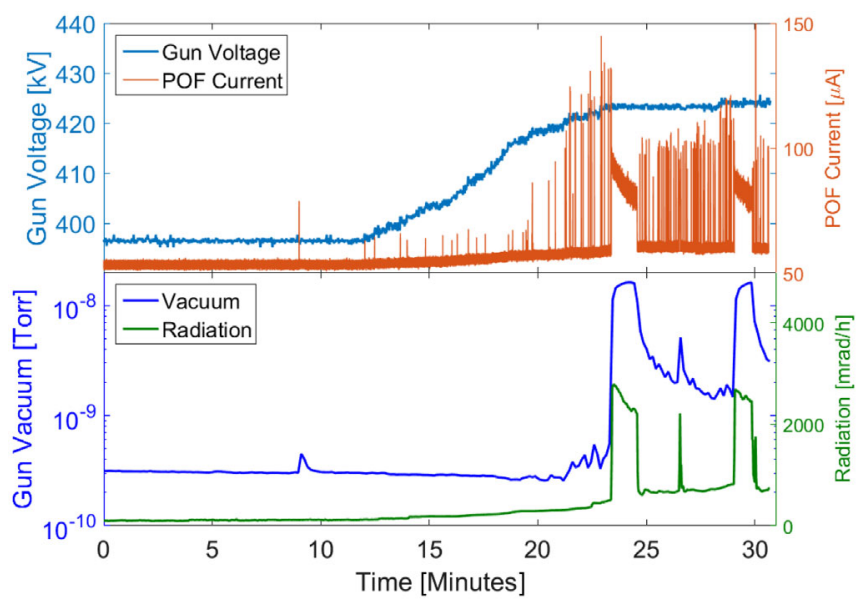

FIG. 7. Four signals are monitored during the dc photoemission gun conditioning: the HVPS voltage, the POF current, the gun radiation level, and the gun vacuum.

During high-voltage dc photoemission gun conditioning, the vacuum trip limit is set to $5 \times 10^{-8}$ Torr, the radiation trip limit is set to $5 \mathrm{rad} / \mathrm{h}$, and the POF current trip limit is set to $2 \mathrm{~mA}$.

In 2018, to save commissioning time, the gun has been conditioned with the running resistor without swapping to the conditioning resistor. With the running resistor $(500 \Omega)$, if there is a discharge in the gun vacuum, the transient current is higher than with the conditioning resistor. Therefore, the HVPS is more prone to trips due to HVPS overcurrent fault. Because of this, the gun conditioning is normally stopped after 5 HVPS trips. With this kind of conditioning with the running resistor, most of the time the gun can be successfully conditioned to a radiation level of less than $100 \mathrm{mrad} / \mathrm{h}$ which is a requirement for the gun operation.
During gun conditioning or operation, sometimes the gun can have higher radiation (up to as much as $10 \mathrm{rad} / \mathrm{h}$ ). It implies the gun is contaminated by additional field emitters. They normally could not be removed by the nominal UHV conditioning procedure.

There are several scenarios that can cause higher radiation in the gun. Firstly, it could be generated during the gun conditioning after increasing the electron gun to a higher voltage followed by a gun trip. The left plot of Fig. 8 shows a typical example of how the radiation increases after a gun trip. The radiation at a gun voltage of $397 \mathrm{kV}$ went up from $70 \mathrm{mrad} / \mathrm{h}$ to $49,300 \mathrm{mrad} / \mathrm{h}$, a 700 -fold increase. At the same time, the current from the power supply measured by the POF increased from 600 to $1500 \mu \mathrm{A}$.

Secondly, inadvertently closing or opening the gun vacuum valves while the HVPS is still on could be another reason. When the vacuum valve is closed with the HVPS high voltage on, particles or emitters can move to the surface of the cathode or the anode electrode, by following the electrostatic field.

Thirdly, during the LEReC dc photoemission gun operation, the radiation could slowly increase to a level higher than $200 \mathrm{mrad} / \mathrm{h}$ from its initial radiation level (right plot of Fig. 8). Particles generated during cathode insertion or possible reversed gas conditioning [48] could be the reason. Finally, a CW beam that caused a gun trip could also result in higher radiation.

If the above four scenarios occur, noble gas processing with helium or krypton can be used to remove the emitters without recleaning the electrodes. The mechanisms of helium or krypton conditioning can be found in Ref. [48]. As indicated in the top plot of Fig. 6 by the red line, the helium gas conditioning has been applied when the gun was conditioned at Cornell.
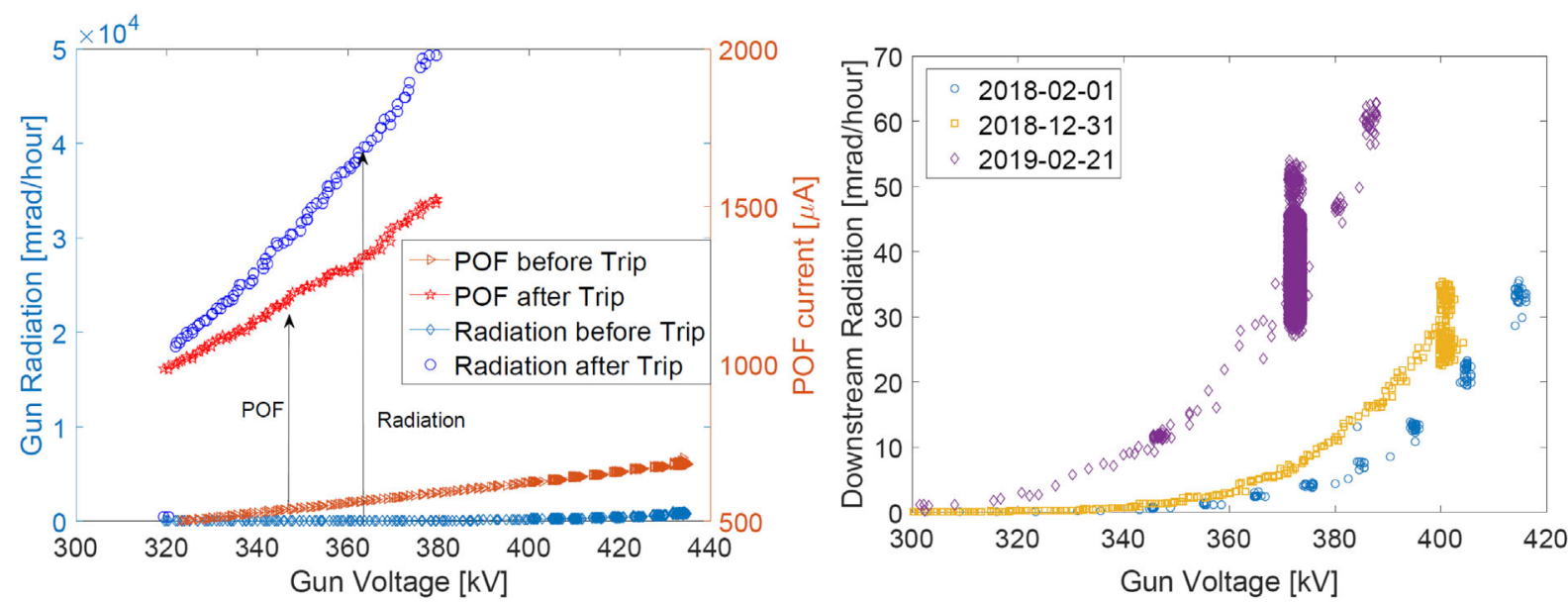

FIG. 8. The gun conditioning and reconditioning with noble gases. Left: radiation and the POF current as a function of the HVPS voltage before and after a gun trip (31 January 2019). Right: radiation as a function of gun voltage after gun conditioning on three different occasions. 
When conditioning the LEReC electron gun with gas, the pressure is set to $5 \times 10^{-5}$ Torr for helium, and it is $2 \times 10^{-5}$ Torr for krypton. Once several gun trips with lower and lower trip voltage occurred, gas conditioning was stopped and followed by a nominal vacuum conditioning. With the operational voltage $(375 \mathrm{kV})$ gas conditioning is also stopped when the radiation is less than $100 \mathrm{mrad} / \mathrm{h}$, which is also the gun radiation requirement in vacuum. Most of the time, to reach the radiation requirement in vacuum, a second or third gas conditioning cycle followed by another vacuum conditioning is necessary.

To achieve lower radiation, a gas filter (Nanochem UHP N2) is used when noble gases are injected, to obtain a gas purity of better than $100 \mathrm{ppt}$ (parts per trillion).

After several helium gas conditionings with filtered gas, a lower radiation level was achieved. The right plot of Fig. 8 shows the radiation as a function of gun voltage after a successful dc gun conditioning cycle on three different occasions. It shows that on 21 February 2019, the radiation was significantly reduced to $30 \mathrm{mrad} / \mathrm{h}(375 \mathrm{kV}$ gun voltage). Given more conditioning time, it could be conditioned to even lower radiation. As low as $8 \mathrm{mrad} / \mathrm{h}$ was achieved in 2018.

\section{BEAM ENERGY AND THE GUN VOLTAGE RIPPLE}

The electron beam energy stability is a critical factor affecting the ion beam cooling efficiency. Therefore, the effect on the electron beam energy from the dc photoemission gun HVPS voltage ripple needs to be addressed. To evaluate the size of effects, the changes in the mean kinetic energy are measured via scanning the gun voltage and recording the horizontal beam position at a dispersive location.

The position change on the deflecting diagnostic line YAG screen can be expressed as

$$
d x=D(x) \frac{d p}{p}=D(x) \beta^{-2} \frac{d E}{E},
$$

where $D(x)$ is the dispersion at the YAG screen, $E$ is the beam total energy, $d E$ is the change in the energy, and $\beta$ is the velocity relative to the speed of light. The measured dispersion at the YAG screen is $0.8 \mathrm{~m}$. During the measurement, the phase and voltage of all cavities are optimized to minimize the energy spread.

With the dechirping $704 \mathrm{MHz}$ warm cavity, the beam energy changes by $0.1 \mathrm{keV}$ per $1 \mathrm{kV}$ requested gun voltage change at the operating voltage. The operating voltage corresponds to a $\Delta V$ at $0 \mathrm{kV}$ on the horizontal axis in Fig. 9. This is close to the average measurement error and could be an indicator that the energy spread has been minimized and is dominated by the beam space charge.

For comparison, the beam energy scan without the $704 \mathrm{MHz}$ dechirping warm cavity is also shown in

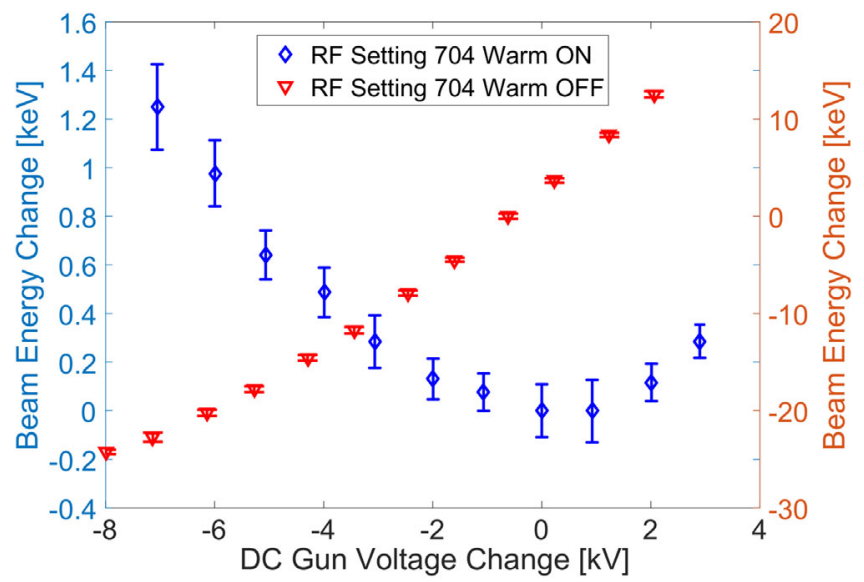

FIG. 9. Change in beam energy as function of change in gun voltage with and without the warm $704 \mathrm{MHz}$ cavity.

Fig. 9 (red line). For the $\Delta V$ from -7 to $3 \mathrm{kV}$ at the gun, the change in the electron beam energy is 35 and $1.25 \mathrm{keV}$ without and with the warm $704 \mathrm{MHz}$ cavity, respectively.

The above results can be explained by Fig. 10. The LEReC $\mathrm{rf}$ system is designed to stretch the beam by implementing an energy chirp to the bunch in the $704 \mathrm{MHz}$ SRF booster cavity. Electrons in the head of the bunch will have higher energy, and those in the tail will have lower energy. The warm $704 \mathrm{MHz}$ cavity removes the chirp by decelerating the head and accelerating the tail. As a side effect, this configuration also reduces the effect of the gun HV ripple (Fig. 9). A bunch that receives too little energy from the gun will arrive later at the booster, where it is accelerated even less and arrives much later at the warm $704 \mathrm{MHz}$ cavity, which then applies more energy to the bunch at the low energy, hence reducing the energy ripple.

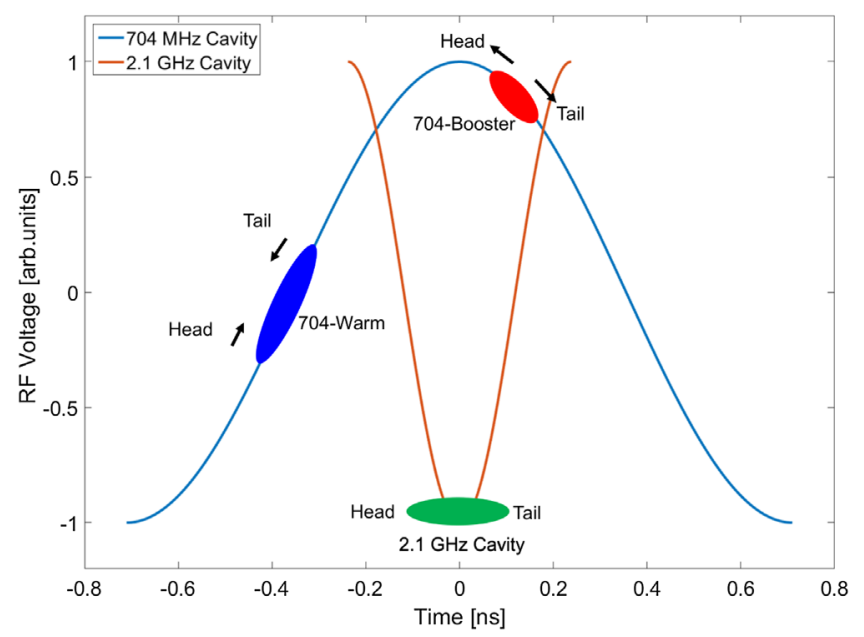

FIG. 10. The phase setup for the $704 \mathrm{MHz}$ SRF booster cavity (red), the $2.1 \mathrm{GHz}$ linearization cavity (green) and warm $704 \mathrm{MHz}$ cavity (blue). 
(a)

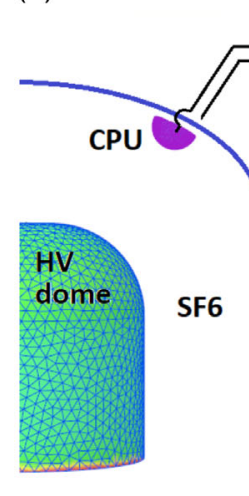

(b)

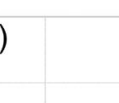

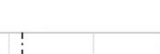

$4 \mathrm{kV}$ 


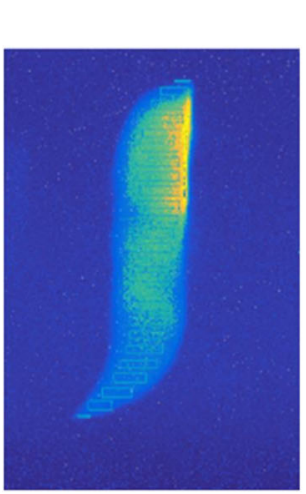

$1.3 \mathrm{~A}$

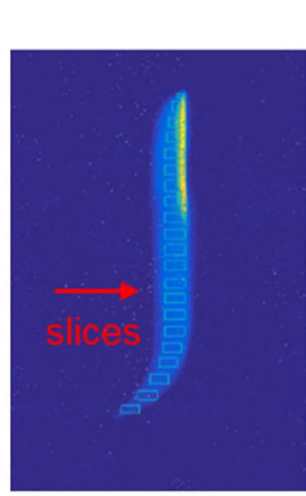

$1.5 \mathrm{~A}$

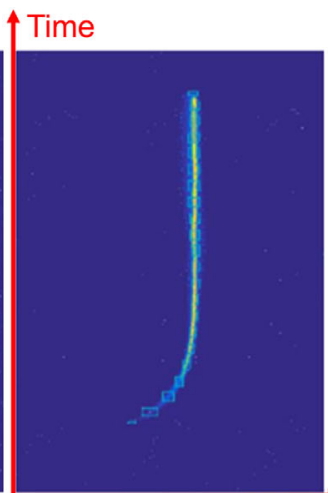

$1.7 \mathrm{~A}$

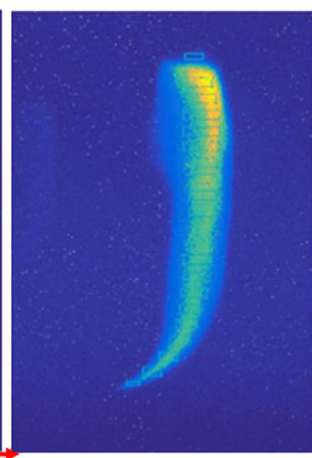

$1.9 \mathrm{~A}$

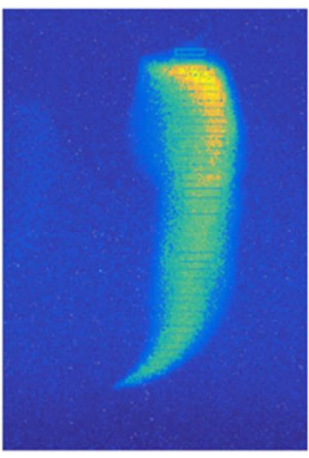

$2.1 \mathrm{~A}$

Solenoid Current $[A]$

FIG. 12. The change in beam size on the YAG screen during the solenoid slice emittance scan. The vertical axis is the time for the beam's longitudinal distribution; the horizontal axis is the beam energy.

particle. $\varnothing=\int q B_{0}(s) / 2 p d s$ is the beam rotation angle with respect to the $z$ axis.

The dipole matrix can be expressed as

$$
M_{\text {dipole }}=\left[\begin{array}{cc}
\cos \theta & \rho_{0} \sin \theta \\
-\frac{1}{\rho_{0}} \sin \theta & \cos \theta
\end{array}\right],
$$

where $\theta=20^{\circ}$ is the beam angle change after the dipole. $\rho_{0}$ is the beam trajectory radius in the dipole and can be calculated as

$$
\rho_{0}=\frac{L}{\theta},
$$

where $L=30 \mathrm{~cm}$ is the path length in the dipole. The dipole also has edge focusing and the matrix on each side can be expressed as

$$
M_{\text {edge }}=\left[\begin{array}{cc}
1 & 0 \\
\frac{\tan (\delta)}{\rho_{0}} & 1
\end{array}\right]
$$

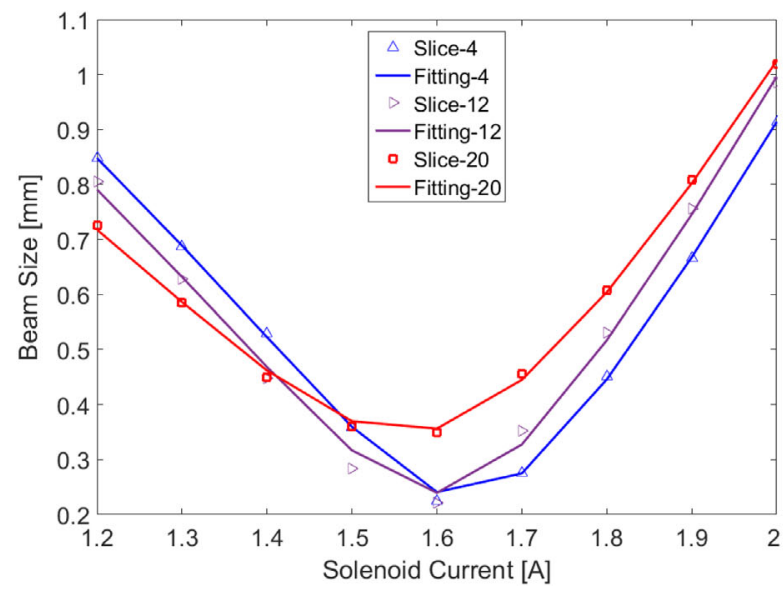

where $\delta=5^{\circ}$ is the pole-edge rotation angle of the dipole magnet used in the diagnostic line. The drift space between the solenoid and the dipole can be expressed as

$$
M_{\text {drift1 }}=\left[\begin{array}{cc}
1 & L_{1} \\
0 & 1
\end{array}\right]
$$

and the drift space between the dipole and the YAG screen is shown as

$$
M_{\mathrm{drift} 2}=\left[\begin{array}{cc}
1 & L_{2} \\
0 & 1
\end{array}\right]
$$

where the drift space lengths are $L_{1}=0.78 \mathrm{~m}$ and $L_{2}=$ $3.43 \mathrm{~m}$, respectively. Therefore, the final matrix can be written as

$$
M=M_{\text {drift } 2} M_{\text {edge }} M_{\text {dipole }} M_{\text {edge }} M_{\text {drift1 }} M_{\text {solenoid }} .
$$

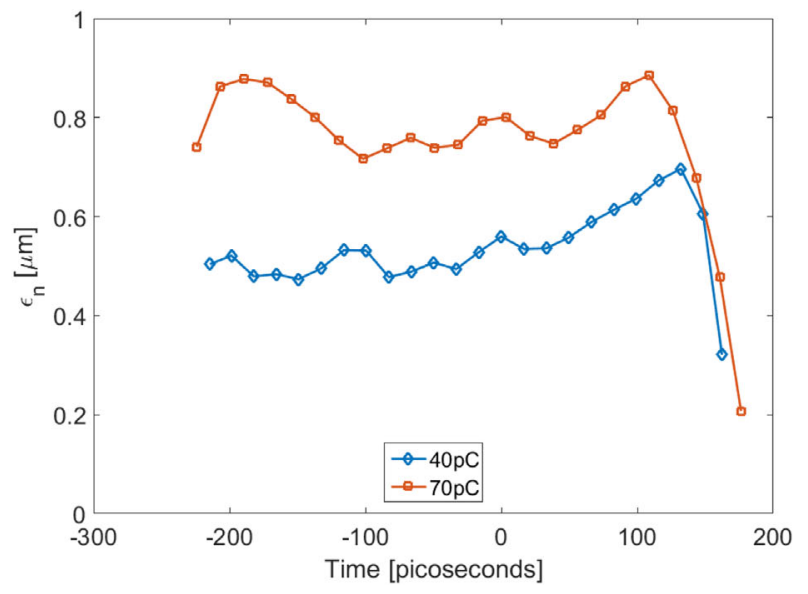

FIG. 13. Solenoid emittances scan and norminalized longitudinal slice emittance. 
To make sure a set of sliced beam size measurement $\sigma_{i}$ corresponds to the same physical longitudinal slice along the bunch, a rectangular area of interest covers the beam region and the total slice number within the rectangle area is set during the solenoid scan (Fig. 12). The slice beam size is calculated by fitting a Gaussian distribution, which is a fast and robust method [55]. During the emittance measurement, the vertical beam is sliced as 24 beamlets for different solenoid currents, as shown in the right plot of Fig. 13.

The left of Fig. 13 is an example ( $40 \mathrm{pC}$ microbunch) that shows the beam size as the function of the solenoid current for the different longitudinal positions (vertical time slices in Fig. 12). The data can be fitted very well to Eq. (5). The calculated slice emittances for the 40 and $70 \mathrm{pC}$ microbunch charges are shown in the right plot of Fig. 13. This demonstrates that the electron beam emittance meets the beam requirement for cooling.

\section{CATHODE INSERTION SYSTEM}

During RHIC operation with cooling, the LEReC machine needs to run continuously without interrupting the physics program frequently. It was estimated from the existing CW beam operation (Cornell University) that the cathode lifetime was as low as one day for high-current operation. Therefore, the photocathode needs to be exchanged frequently.

To minimize the cathode exchange time, and to ensure that the LEReC electron beam can be continuously operated with little interruption, two cathode deposition systems, three multicathode carriers, and a rapid cathode puck insertion system were built [56]. A schematic of the LEReC cathode insertion system with a cathode carrier attached is depicted in Fig. 14(a). The total time for a cathode exchange is about 45 minutes.
For the cathode deposition system, using a high quantum efficiency (QE) $\mathrm{CsK}_{2} \mathrm{Sb}$ recipe [57], one cathode a day can be grown with good repeatability. The deposition system can grow several cathodes continuously without opening the source chamber to exchange the alkali material. All the cathodes have an acceptable QE in a range of $4 \%-8 \%$.

The cathode carrier [58] can be attached to the cathode deposition system. It takes about 14 days to prepare one cathode carrier with 9 cathodes. After transport, the carrier can then be attached to the rapid cathode puck insertion system for cathode replacement.

The cathode carrier includes a multipuck storage device [MPSD, Fig. 14(b)], a $10^{-11}$ Torr-scale vacuum chamber, and a manipulator. The MPSD is a rotatable storage wheel with 12 cathode holders inside the UHV chamber. Normally, the MPSD has two empty positions to place the used cathode from the electron gun or the used cathode that is temporarily held in the cathode insertion system. There is another dummy cathode for possible gun conditioning [Fig. 14(b)]. To provide the capability of checking the performance of each photocathode inside the MPSD before insertion, a QE measurement device is also provided in the MPSD.

During operation, we found that the cathode can last at least for 3 days in $20 \mathrm{~mA} \mathrm{CW}$ operation. Therefore, the whole system, including two cathode deposition systems, three cathode carriers, and a fast cathode insertion system can ensure the timely supply of cathodes for continuous LEReC operation.

\section{DC PHOTOEMISSION GUN OPERATION}

During the LEReC 2019 run, the high-voltage dc photoemission gun system provided stable operation for more than 7 months. Figure 15(a) depicts the long-term gun voltage evolution during the operation period. During gun

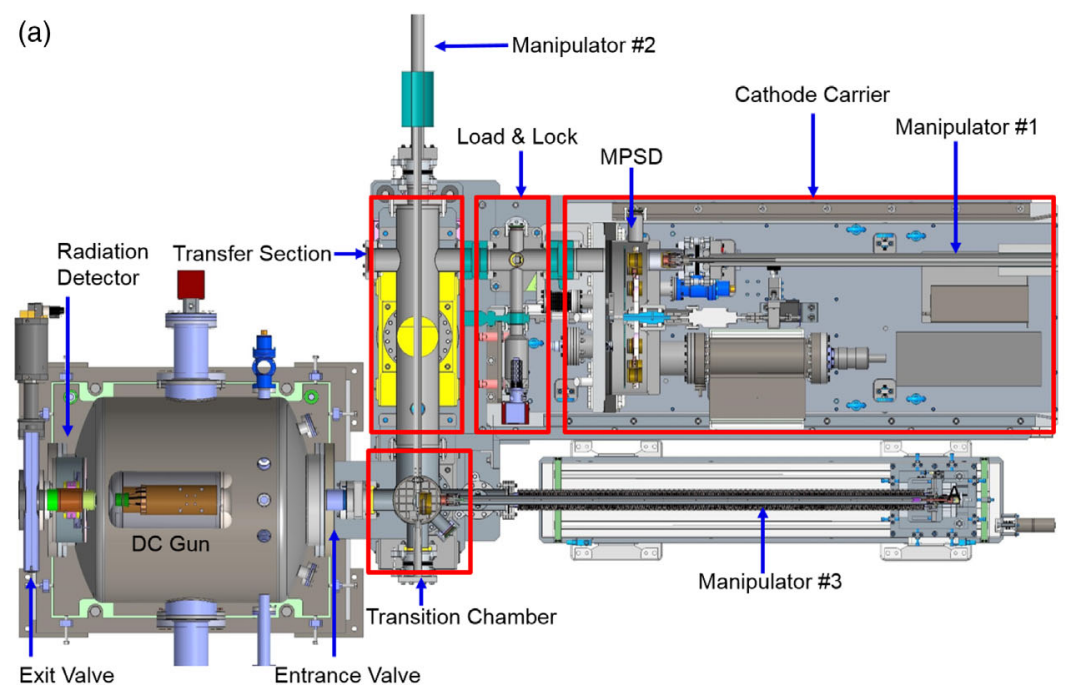

(b)

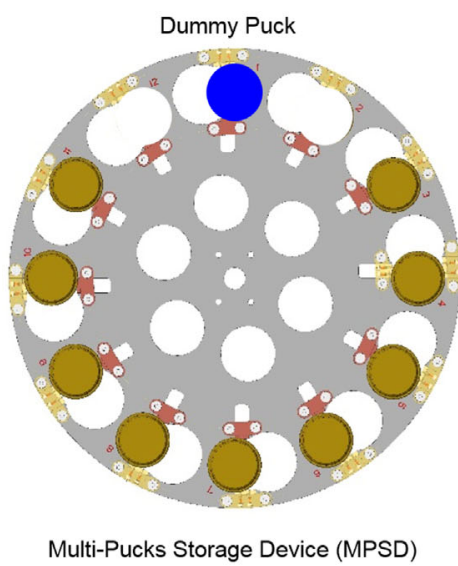

Fig. 14. Rapid cathode puck insertion system for the LEReC dc photoemission gun. 


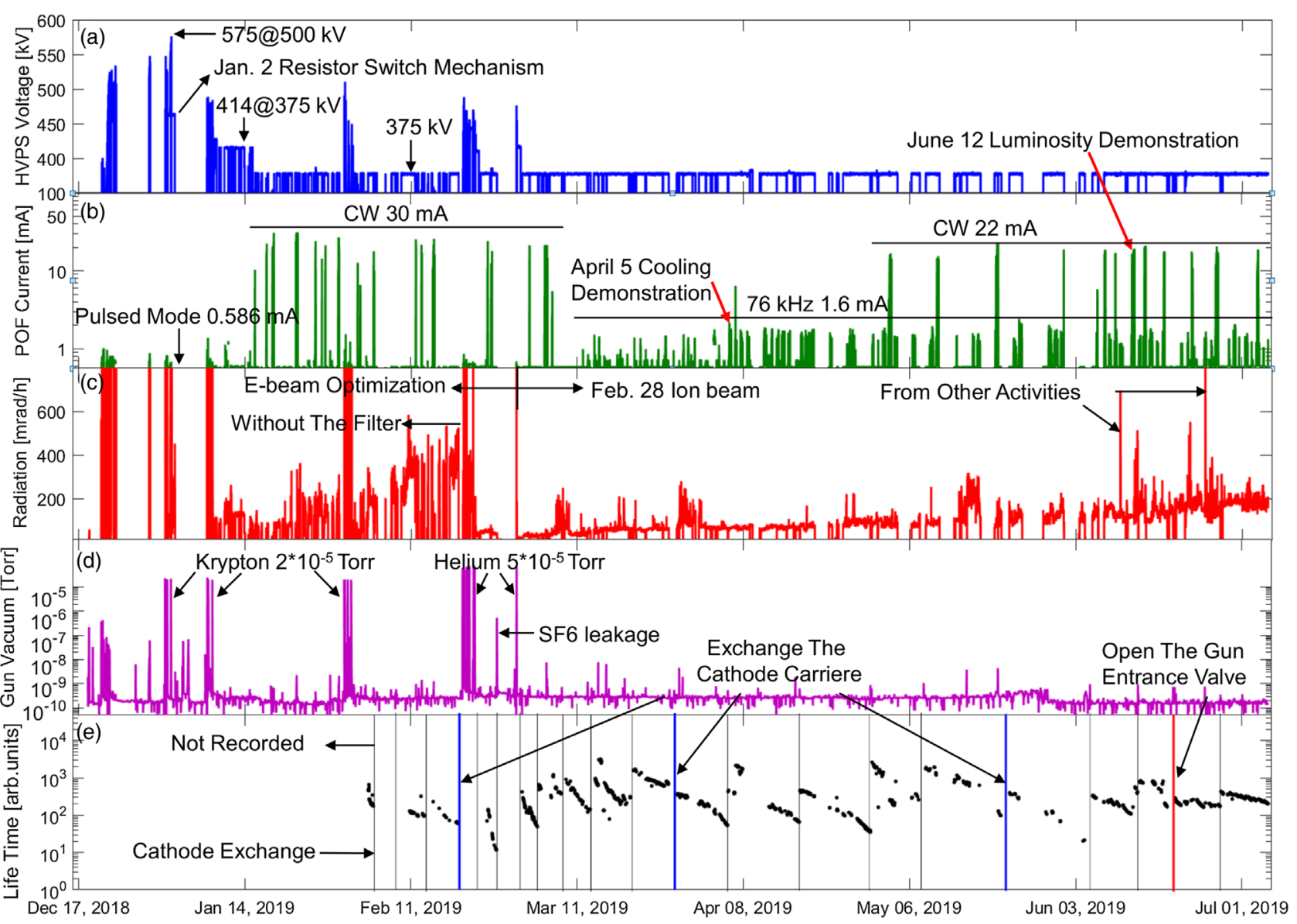

FIG. 15. Overview of LEReC operation with the high-voltage dc photoemission gun.

conditioning, the HVPS voltage was raised to $575 \mathrm{kV}$. This corresponds to $500 \mathrm{kV}$ on the gun electrode with $100 \mathrm{M} \Omega$ conditioning resistor. After 2 January 2019, the switchable resistor mechanism was installed with a $66.7 \mathrm{M} \Omega$ resistor. The electron gun was operated with the conditioning resistor for a while, which is indicated by the $414 \mathrm{kV}$ HVPS voltage in the plot ( $375 \mathrm{kV}$ gun voltage). The nominal HVPS voltage was kept at $375 \mathrm{kV}$ after conditioning.

Figure 15(b) summarizes the POF-measured current when the three operational modes are used. In pulsed mode, the POF current is $0.586 \mathrm{~mA}$ which is essentially the gun-side voltage divider (two resistor chains in Fig. 4) current. In $76 \mathrm{kHz}$ mode, the total POF current is between 1.0 and $1.6 \mathrm{~mA}$. In $76 \mathrm{kHz}$ mode, bunched beam nonmagnetized electron cooling was demonstrated on 5 April 2019 for the first time worldwide. The maximum CW current during 2019 was $30 \mathrm{~mA}$ which is the same as 2018 operations. The $\mathrm{CW}$ beam used for the luminosity optimization was 14-20 mA.

Figure 15(c) shows the radiation levels during the 2019 operation. With the constant gun voltage of $375 \mathrm{kV}$ (after 28 February), it turns out that the radiation can drift from 30 to $200 \mathrm{mrad} / \mathrm{h}$. A similar behavior was seen during the
2018 LEReC operation, although its initial radiation was about $8 \mathrm{mrad} / \mathrm{h}$ for the same gun voltage.

Most of the time after gun conditioning, the gun radiation is around $100 \mathrm{mrad} / \mathrm{h}$. It is also confirmed that some high radiation spikes were caused by other accelerator activities. There were several gun HVPS trips during the 2019 operation, but these cannot be correlated with any radiation activities. With the recorded radiation levels and gun trips, negative effects on the cathode lifetime are not found.

Figure 15(d) shows the gun vacuum pressure from the ion gauge of the gun. It shows the dc photoemission gun conditioning with the $2 \times 10^{-5}$ Torr krypton and the $5 \times 10^{-5}$ Torr helium. The gas filter was not used during conditioning with the krypton gas, but it was used with the helium gas. During 2018, the gun was conditioned with krypton and the gas filter. Without the gas filter, the radiation increases faster. One of the vacuum spikes in Fig. 15(d) was caused by a SF6 leakage to the gun.

Figure 15(e) marks the time when the cathodes (vertical black lines) and the cathode carrier (vertical blue lines) were exchanged. The cathode lifetime is also shown (black dots). It is roughly estimated from the pulsed beam charge and the laser intensity recorded on the cathode YAG screen. 
From the plot, one can find that the cathode life time is not good after the gas conditioning. However, with more time, the cathode lifetime improves. The cathode lifetime is further improved after opening the gun entrance valve [red vertical line in Fig. 15(e)], even though the radiation level is slightly higher. The gun entrance valve is between the cathode insertion system and the electron gun [Fig. 14(a)]. It is believed that opening the gun valve results in a better vacuum condition in the gun although it could not be measured by the ion gauges, thus a better cathode lifetime.

During operation, one cathode can be used more than 10 days in pulsed mode. Nominally, when the microbunch charge is less than $100 \mathrm{pC}$ with $100 \%$ of the available laser intensity, the cathode was exchanged. Sometimes, the cathode was exchanged even when it was still good for operation because of a convenient RHIC ring access opportunity.

\section{HIGH-CURRENT OPERATION}

High-current dc photoemission gun operations were studied using the LEReC injection line beginning in 2017. The $704 \mathrm{MHz}$ SRF booster cavity was not installed in the beam line at that time. An average current of $10 \mathrm{~mA}$ was achieved on 11 August 2017. The CW beam was provided for 40 minutes.

In 2018, the $704 \mathrm{MHz}$ SRF booster cavity was installed. By September 2018, we were able to deliver a $30 \mathrm{~mA}$ beam to the injection beam dump for about 4 consecutive hours, with reduced SRF booster voltage. As depicted in Fig. 16, $25 \mathrm{~mA} \mathrm{CW}$ beam was delivered to the low-power dump for $7.8 \mathrm{~h}$ without interruptions. The cathode lifetime was estimated to be $142 \mathrm{~h}$. A $1.6 \mathrm{MeV}$ high CW current beam $(20 \mathrm{~mA})$ was also propagated to the high-power beam dump during the 2018 commissioning.

During the 2019 cooling optimization period, it was found that a bunch charge of $60 \mathrm{pC}$ per microbunch yields

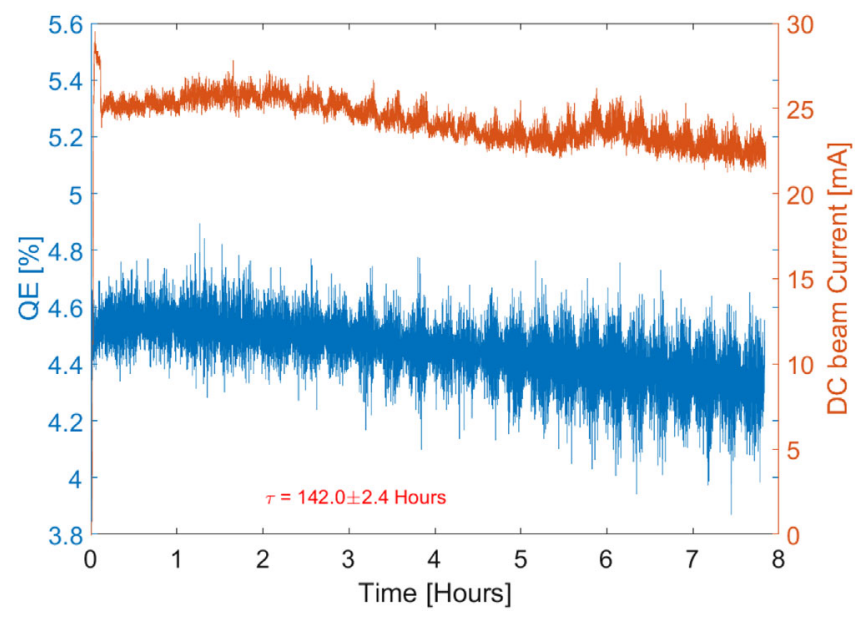

FIG. 16. Beam current in $\mathrm{CW}$ operation (red line) over 7.84 hours, and QE (blue line) with a fitted cathode current lifetime of $142 \mathrm{~h}$.

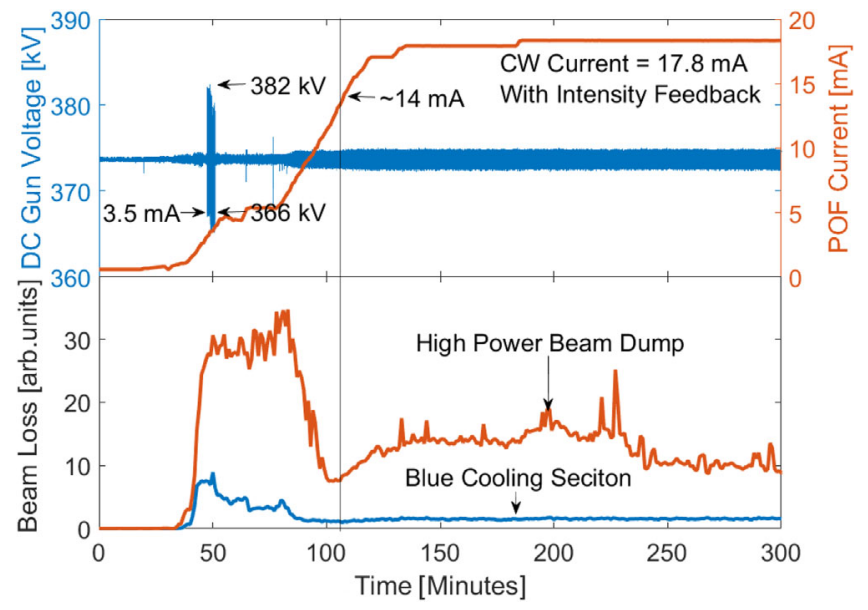

FIG. 17. Top: CW beam current ramp-up for cooling optimization. Bottom: beam loss in the blue cooling section and the high-power beam dump.

the best cooling results. Therefore, the $14-20 \mathrm{~mA} \mathrm{CW}$ beams [Fig. 15(b)], corresponding to $50-80 \mathrm{pC}$ per microbunch, were regularly used for operation. During these activities, the high-voltage dc photoemission gun provided stable $\mathrm{CW}$ beams without gun-caused $\mathrm{CW}$ beam trips.

Figure 17 depicts a typical CW beam current ramp-up during cooling and luminosity optimization. The top plot includes the gun voltage (blue line) measured by the resistor chain ( $\mathrm{V}$ chain) and the POF current (red line). The gun voltage measurement indicates the presence of an instability when the $\mathrm{CW}$ beam current is approximately $3.5 \mathrm{~mA}$. Within the instability, the gun voltage oscillates between 366 and $382 \mathrm{kV}$ amplitude. The data also indicates that there will be higher gun voltage ripples at higher CW beam current. During this CW current ramp in 2019, the laser intensity feedback is engaged. However, no such feedback was engaged in the case shown in Fig. 16.

The bottom plot shows the beam loss for the end of the blue cooling section and the high-power beam dump region. Since the lattice is optimized for a high bunch charge of 40-100 $\mathrm{pC}$, higher beam losses occur at the two locations (the blue cooling section and the high-power beam dump) at the beginning of the $\mathrm{CW}$ current ramp. After $14 \mathrm{~mA}$, the beam loss in the blue cooling section stays constant.

Sometimes, the gun high-voltage power supply stays on during a CW beam caused machine protection system [18] trip. Figure 18 shows a gun voltage spike during such a trip while running $17.8 \mathrm{~mA} \mathrm{CW}$ beam. The $\mathrm{CW}$ beam trip is triggered by the LEReC machine protection system. The $\mathrm{CW}$ beam current is the POF current $(18.3 \mathrm{~mA})$ minus its background current $(0.586 \mathrm{~mA})$. After the trip, the voltage is regulated back to its original setting by the HVPS with less ripples. Therefore, a CW beam trip does not always cause a gun voltage trip.

During periods of $\mathrm{CW}$ beam operation, we found that in some cases the cathode QE increased at the beginning of 


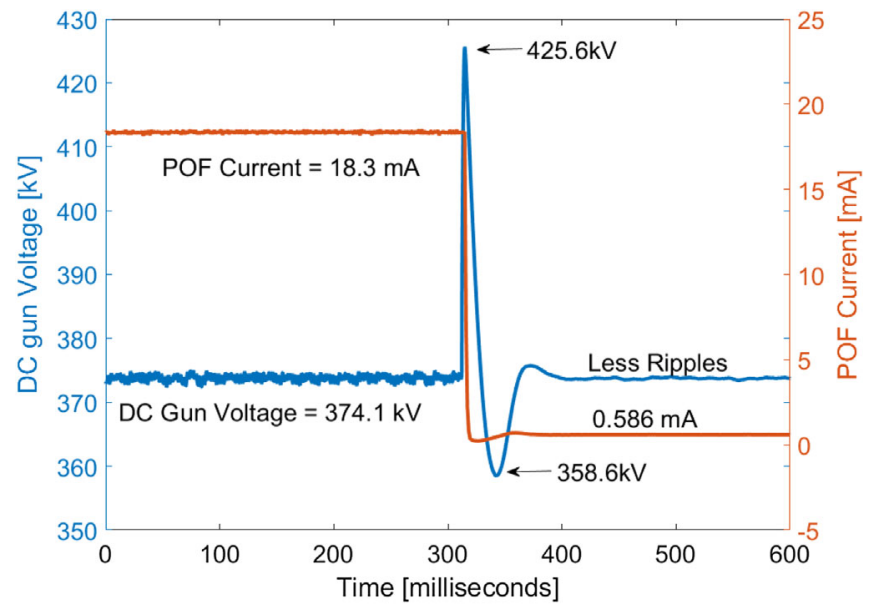

FIG. 18. A dc photoemission gun voltage during trip while running $\mathrm{CW}$ beam.

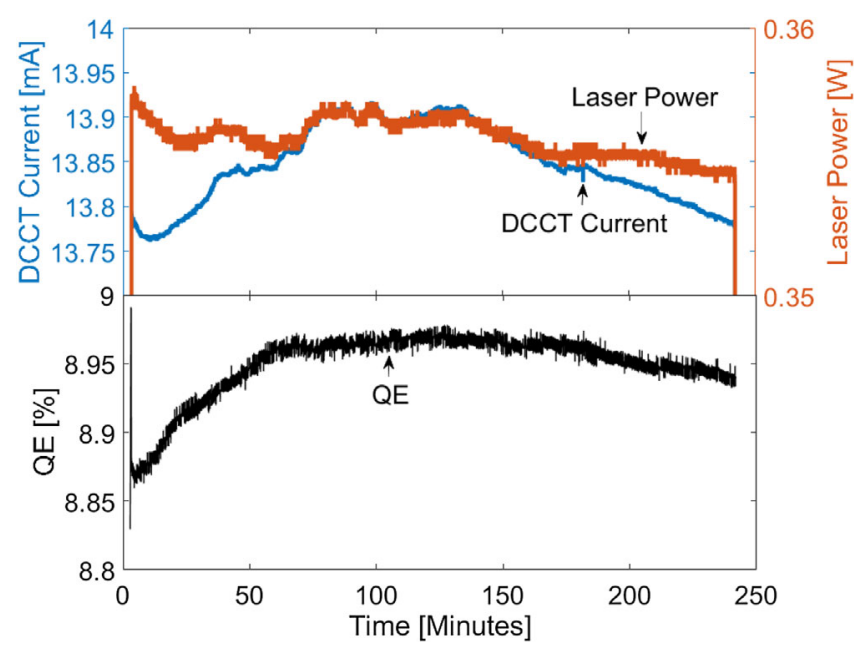

FIG. 19. Top: CW beam current and laser power used for QE calculation. Bottom: cathode $\mathrm{QE}$ increases at the beginning of a $\mathrm{CW}$ beam operation.

the $\mathrm{CW}$ beam operation. As is shown in Fig. 19, the cathode QE increased by an absolute vaule of about $0.1 \%$ after about 1 hour of operation. This has happened for different initial cathode $\mathrm{QE}$ values (3\%-9\%) and different CW beam currents $(10 \mathrm{~mA}-20 \mathrm{~mA})$ with varying increment $(0.1 \%-0.2 \%)$. The reason for the cathode QE increment can be found in Refs. [59,60].

\section{SUMMARY}

A high-voltage dc photoemission gun, based on a previous Cornell University gun, was built and commissioned for the Low Energy RHIC electron Cooler. The high-voltage dc photoemission gun has stringent requirements for the beam quality at high current and must be operated reliably for the RHIC physics program. It was successfully used in the world's first demonstration of hadron beam cooling with rf accelerated electron bunches.

In pulsed mode, the demonstrated slice emittance and currents met the requirements for LEReC. In CW mode, it has provided $25 \mathrm{~mA}$ over $7.8 \mathrm{~h}$ without interruption, and 14-20 mA routinely during cooling commissioning.

For the dc photoemission gun, a cathode production and exchange system were developed consisting of two cathode deposition systems, three multicathode carriers, and a mechanism allowing for a cathode exchange in 45 minutes.

The LEReC dc photoemission gun has provided stable beam operation in pulsed mode, $76 \mathrm{kHz}$ mode, and $\mathrm{CW}$ mode over a period of 7 months.

\section{ACKNOWLEDGMENTS}

This work was supported and made possible by many in the Collider-Accelerator Department and Instrumentation Department at Brookhaven National Laboratory. The authors also appreciate valuable discussions with staff at Cornell University and in particular B. Dunham, SLAC, and C. Hernandez-Garcia (JLab). This work was supported by the U.S. Department of Energy under Contract No. DESC0012704.

[1] M. Harrison, T. Ludlam, and S. Ozaki, RHIC project overview, Nucl. Instrum. Methods Phys. Res., Sect. A 499, 235 (2003).

[2] M. Bai et al., Polarized Proton Collisions at $205 \mathrm{GeV}$ at RHIC, Phys. Rev. Lett. 96, 174801 (2006).

[3] W. Fischer and J. W. Jowett, Ion colliders, Rev. Accel. Sci. Techol. 07, 49 (2014).

[4] RHIC Runs overview, https://www.rhichome.bnl.gov/ RHIC/Runs/.

[5] M. Stephanov, QCD phase diagram and the critical point, Int. J. Mod. Phys. A 20, 4387 (2005).

[6] M. Stephanov, K. Rajagopal, and E. Shuryak, Signatures of the Tricritical Point in QCD, Phys. Rev. Lett. 81, 4816 (1998).

[7] G. Stephans, critRHIC: The RHIC low energy program, J. Phys. G 32, S447 (2006).

[8] L. Kumar (STAR Collaboration), STAR results from the RHIC beam energy scan-I, Nucl. Phys. A904, 256c (2013).

[9] A. W. Chao and M. Tigner, Handbook of Accelerator Physics and Engineering, 2nd printing (World Scientific Publishing Co. Pte. Ltd., Singapore, 2002).

[10] T. Satogata, L. Ahrens, M. Bai et al., RHIC challenges for low energy operation, in Proceedings of the 22nd Particle Accelerator Conference, PAC-2007, Albuquerque, NM (IEEE, New York, 2007), pp. 1877, https://ieeexplore.ieee .org/stamp/stamp.jsp?tp=\&arnumber $=4440928 \& \operatorname{tag}=1$.

[11] A. V. Fedotov, I. Ben-Zvi, X. Chang et al., Beam dynamics limits for low energy RHIC operation, in Proceedings of Hadron Beam 2008, Nashville, Tennessee, USA (2008), http://accelconf.web.cern.ch/AccelConf/HB2008/papers/ wga10.pdf. 
[12] A. V. Fedotov, M. Bai, M. Blaskiewicz et al., Beam lifetime and limitations during low-energy RHIC operation, in Proceedings of 2011 Particle Accelerator Conference, New York, NY, USA (2011), pp. 2285-2287, https:// accelconf.web.cern.ch/accelconf/PAC2011/papers/thp081 .pdf.

[13] A. V. Fedotov, S. Belomestnykh, I. Ben-Zvi et al., Bunched beam electron cooling for Low Energy RHIC operation, Proceedings of PAC2013, Pasadena, CA USA (2013), pp. 363-365, http://accelconf.web.cern.ch/AccelConf/ PAC2013/papers/tuoaa1.pdf.

[14] C. Liu, M. Blaskiewicz, K. A. Drees et al., Improving Luminosity of Beam Energy Scan II at RHIC, 10th Int. Particle Accelerator Conf. IPAC2019, Melbourne, Australia (2019), http://accelconf.web.cern.ch/AccelConf/ ipac2019/papers/mopmp044.pdf.

[15] A. V. Fedotov et al., Accelerator physics design requirements and challenges of RF based electron cooler LEReC, in Proceedings of North American Particle Accelerator Conf. (NAPAC'16), Chicago, IL, USA, 2016, pp. 867-869, https://doi.org/10.18429/JACoW-NAPAC2016-WEA4CO05.

[16] D. Kayran, Z. Altinbas, D. Bruno et al., First results of commissioning DC photo-gun for RHIC Low Energy electron Cooler (LEReC), 59th ICFA Advanced Beam Dynamics Workshop on Energy Recovery Linacs ERL2017, Geneva, Switzerland (2017), pp. 65-69, http://accelconf.web.cern.ch/AccelConf/erl2017/papers/ weiccc004.pdf.

[17] J. Kewisch, A. V. Fedotov, D. Kayran, and S. Seletskiy, Beam optics for the RHIC Low Energy electron Cooler (LEReC), Proceedings of NAPAC2016, Chicago, IL, USA (2016), http://accelconf.web.cern.ch/AccelConf/ napac2016/papers/wepob56.pdf.

[18] S. Seletskiy, Z. Altinbas, M. Costanzo et al., Conceptual design of LEReC fast machine protection system, in Proceedings of IBIC2016, Barcelona, Spain (2016), pp. 665-668, https://doi.org/10.18429/JACoW-IBIC2016WEPG19.

[19] A. Fedotov et al., Status of bunched beam Low Energy RHIC electron Cooling (LEReC), Project, COOL17, Bonn, Germany, WEM11, http://accelconf.web.cern.ch/ AccelConf/cool2017/talks/wem11_talk.pdf.

[20] C. Liu, A. Fedotov, D. Gassner et al., Transverse beam emittance measurements with multi-slit and moving-slit devices for LEReC, in 7th Int. Beam Instrumentation Conf. IBIC2018, Shanghai, China (2018), pp. 486-489, http:// accelconf.web.cern.ch/AccelConf/ibic2018/papers/wepb21 .pdf.

[21] D. Kayran et al., First results from commissioning of Low Energy RHIC electron Cooler (LEREC), presented at the 10th International Particle Accelerator Conf. (IPAC'19), Melbourne, Australia, May 2019, https://doi.org/10.18429/ JACoW-IPAC2019-MOPRB085.

[22] A. Fedotov, Z. Altinbas, M. Blaskiewicz et al., First electron cooling of hadron beams using a bunched electron beam, presented at the North American Particle Accelerator Conference (NAPAC'19), Lansing, MI, 2019, paper THZBA5, https://www.osti.gov/servlets/purl/1572294.
[23] B. Xiao, I. Ben-Zvi, M. Blaskiewicz et al., HOM Consideration of $704 \mathrm{MHz}$ and $2.1 \mathrm{GHz}$ Cavities for LEReC Linac, in Proceedings of IPAC2016, Busan, Korea (2016), pp. 528-531, https://doi.org/10.18429/JACoW-IPAC2016MOPMY009.

[24] B. Xiao, I. Ben-Zvi, M. Blaskiewicz et al., RF design of normal conducting $704 \mathrm{MHz}$ and $2.1 \mathrm{GHz}$ cavities for LEReC linac, in Proceedings of IPAC2016, Busan, Korea (2016), pp. 532-535, http://accelconf.web.cern.ch/ AccelConf/ipac2016/papers/mopmy010.pdf.

[25] J. C. Brutus, S. A. Belomestnykh, I. Ben-Zvi et al., Mechanical design and 3-D coupled RF, thermal-structural analysis of normal conducting $704 \mathrm{MHz}$ and $2.1 \mathrm{GHz}$ cavities for LEReC linac, in Proceedings of IPAC2016, Busan, Korea (2016), pp. 525-527, http://accelconf.web .cern.ch/AccelConf/ipac2016/papers/mopmy007.pdf.

[26] T. Xin, B. Xiao, J. M. Brennan et al., Measuring the electrical center and field flatness of $704 \mathrm{MHz}$ deflecting cavity for LEReC with wire stretching system, in 9th International Particle Accelerator Conference IPAC2018, Vancouver, BC, Canada (2018), pp. 1320-1322, http:// inspirehep.net/record/1690829/files/tupmf034.pdf.

[27] B. Xiao, S. Belomestnykh, J. M. Brennan et al., Design and test of $704 \mathrm{MHz}$ and $2.1 \mathrm{GH} 1 \mathrm{z}$ normal conducting cavities for low energy RHIC electron cooler, Phys. Rev. Accel. Beams 22, 030101 (2019).

[28] B. Xiao, A. Fedotov, H. Hahn et al., Higher order mode damper for low energy RHIC electron cooler superconducting radio frequency booster cavity, Phys. Rev. Accel. Beams 22, 050101 (2019).

[29] B. Dunham, J. Barley, A. Bartnik et al., Record highaverage current from a high brightness photoinjector, Appl. Phys. Lett. 102, 034105 (2013).

[30] C. Gulliforda, A. Bartnikb, I. Bazarov, B. Dunham, and L. Cultrera, Demonstration of cathode emittance dominated high bunch charge beams in a DC gun-based photoinjector, Appl. Phys. Lett. 106, 094101 (2015).

[31] C. Gulliford, A. Bartnik, I. Bazarov et al., Demonstration of low emittance in the Cornell energy recovery linac injector prototype, Phys. Rev. ST Accel. Beams 16, 073401 (2013).

[32] I. V. Bazarov and C. K. Sinclair, Multivariate optimization of a high brightness dc gun photoinjector, Phys. Rev. ST Accel. Beams 8, 034202 (2005).

[33] J. Maxson, I. Bazarov, B. Dunham, J. Dobbins, X. Liu, and K. Smolenski, Design, conditioning, and performance of a high voltage, high brightness dc photoelectron gun with variable gap, Rev. Sci. Instrum. 85, 093306 (2014).

[34] C. Gulliford, A. Bartnik, I. Bazarov and J. Maxson, Multiobjective optimization design of an $\mathrm{rf}$ gun based electron diffraction beam line, Phys. Rev. Accel. Beams 20, 033401 (2017).

[35] C. Gulliford, A. Bartnik, and I. Bazarov, Multiobjective optimization of an novel cryocooled dc gun based ultrafast electron diffraction beam line, Phys. Rev. Accel. Beams 19, 093402 (2016).

[36] A. Bartnik, C. Gulliford, I. Bazarov, L. Cultera, and B. Dunham, Operational experience with nanocoulomb bunch charges in the Cornell photoinjector, Phys. Rev. ST Accel. Beams 18, 083401 (2015). 
[37] C. Gulliford, Characterization of the beam dynamics in the Cornell Energy Recovery Linac Injector prototype, thesis, Doctor of Philosophy, Cornell University, https://www .classe.cornell.edu/ ib38/theses/Gulliford_thesis.pdf.

[38] N. Nishimori, R. Nagai, M. Yamamoto et al., Development of a $500-\mathrm{kV}$ photocathode DC gun for ERLS, J. Phys. Conf. Ser. 298, 012005 (2011).

[39] N. Nishimori, R. Nagai, S. Matsuba, R. Hajima, M. Yamamoto, Y. Honda, T. Miyajima, H. Iijima, M. Kuriki, and M. Kuwahara, Experimental investigation of an optimum configuration for a high-voltage photoemission gun for operation at $\geq 500 \mathrm{kV}$, Phys. Rev. ST Accel. Beams 17, 053401 (2014).

[40] M. Yamamoto and N. Nishimori, High voltage threshold for stable operation in a dc electron gun, Appl. Phys. Lett. 109, 014103 (2016).

[41] N. Nishimori, R. Nagai, S. Matsuba, R. Hajima, M. Yamamoto, T. Miyajima, Y. Honda, H. Iijima, M. Kuriki, and M. Kuwahara, Generation of a 500-keV electron beam from a high voltage photoemission gun, Appl. Phys. Lett. 102, 234103 (2013).

[42] R. Nagai, R. Hajima, N. Nishimori et al., High-voltage testing of a 500-kV dc photocathode electron gun, Rev. Sci. Instrum. 81, 033304 (2010).

[43] M. Alemoto, D. Arakawa, S. Asaoka et al., Construction and commissioning of the compact energy-reovery linac at KEK, Nucl. Instrum. Methods Phys. Res., Sect. A 877, 197 (2018).

[44] J. Hwang, E. Kim, T. Miyajima et al., Analysis on effects of transverse electric field in an injector cavity of compactERL at KEK, Nucl. Instrum. Methods Phys. Res., Sect. A 753, 97 (2014).

[45] G. Neil et al., The JLab high power ERL light source, Nucl. Instrum. Methods Phys. Res., Sect. A 557, 9 (2006).

[46] C. K. Sinclair, A $500 \mathrm{kV}$ photoemission electron gun for the CEBAF FEL, Nucl. Instrum. Methods Phys. Res., Sect. A 318, 410 (1992).

[47] C. Hernandez-Garcia, D. Bullard, F. Hannon, Y. Wang, and M. Poelker, High voltage performance of a dc photoemission electron gun with centrifugal barrel-polished electrodes, Rev. Sci. Instrum. 88, 093303 (2017).

[48] M. BastaniNejad, A. Al. Elmustafa, E. Forman, J. Clark, S. Covert, J. Grames, J. Hansknecht, C. Hernandez-Garcia, M. Poelker, and R. Suleiman, Improving the performance of staineless-stell DC high voltage photoelectron gun cathode electrodes via gas conditioning with helium or krypton, Nucl. Instrum. Methods Phys. Res., Sect. A 762, 135 (2014).
[49] Z. Zhao, B. Sheehy, and M. Minty, Generation of $180 \mathrm{~W}$ average green power from a frequency-doubled picosecond rod fiber amplifier, Opt. Express 25, 8138 (2017).

[50] Z. Zhao, K. Mernick, M. Costanzo, and M. Minty, An ultrafast laser pulse picker technique for high-averagecurrent high-brightness photoinjectors, Nucl. Instrum. Methods Phys. Res., Sect. A (to be published).

[51] F. R. Bassan, J. B. Rosolem, C. F. Barbosa and R. A. V. Teixeira, A power over fiber voltage and current sensor using multiplexed PWM signals, Proc. SPIE Int. Soc. Opt. Eng. 10654, 1065414 (2018).

[52] T. Miller et al., Overview of the beam instrumentation and commissioning results from the BNL Low Energy RHIC electron Cooling Facility, IBIC2019, in September in Malmo, Sweden.

[53] C. Liu, A. Fedotov, D. Gassner et al., Transverse beam emittance measurements with multi-slit and moving-slit devices for LEReC, IBIC2018, Shanghai, China, https:// doi.org/10.18429/JACoW-IBIC2018-WEPB21.

[54] D. Xiang, Y.-C. Du, L.-X. Yan, R.-K. Li, W.-H. Huang, C.-X. Tang, and Y.-Z. Lin, Transverse phase space tomography using a solenoid applied to a thermal emittance measurement, Phys. Rev. ST Accel. Beams 12, 022801 (2009).

[55] E. Prat, M. Aiba, S. Bettoni, B. Beutner, S. Reiche, and T. Schietinger, Emittance measurement at the SwissFEL Injector Test Facility, Phys. Rev. ST Accel. Beams 17, 104401 (2014).

[56] E. Wang et al., Bi-alkali antimonide photocathodes for LEReC DC gun, in Proceedings of the 10th International Particle Accelerator Conf. (IPAC2019), Melbourne, Australia, 2019, https://doi.org/10.18429/JACoW-IPAC2019-TUPTS101.

[57] E. Wang, M. Gaowei, A. Fedotov et al., Multi-alkalai photocathodes production for LEReC DC gun, OSTI.gov Technical Report, 2018, https://doi.org/10.2172/1438329.

[58] C. J. Liaw et al., Cathode puck insertion system design for the LEReC photoemission DC electron gun, in Proceedings of NAPAC2016, pp. 1021-1023, 2016.

[59] G. Ciovati, Improved oxygen diffusion model to explain the effect of low-temperature baking on high field losses in niobium superconducting cavities, Appl. Phys. Lett. 89, 022507 (2006).

[60] E. Wang, T. Rao, and I. Ben-zvi, Enhancement of photoemission from and postprocessing of $\mathrm{K} 2 \mathrm{CsSb}$ photocathode using excimer laser, Phys. Rev. ST Accel. Beams 17, 023402 (2014). 